\title{
Ohralajikkeiden välillä suuria eroja jyvän kuidun sulatusnopeudessa
}

Arja Seppälä ${ }^{1)}$, Anita Stevneb $\varnothing^{2)}$, Odd Magne Harstad ${ }^{2)}$ ja Pekka Huhtanen ${ }^{1)}$

${ }^{11}$ MTT/KEL/Eläinravitsemus, 31600 Jokioinen; arja.seppala@mtt.fi; pekka.huhtanen@mtt.fi

${ }^{2)}$ Norwegian University of Life Sciences; anita.stevnebo@umb.no; odd.harstad@umb.no

\section{Tiivistelmä}

Tässä tutkimuksessa selvitettiin in vitro -kaasuntuotantomenetelmällä eri ohralajikkeiden jyvien välisiä eroja solun sisällyksen ja kuidun sulatusnopeuksissa. Tutkimus tehtiin osana isompaa tutkimushanketta ja yhteistyötahona oli Norwegian University of Life Sciences.

Kokeessa oli mukana 12 ohralajiketta (Alamo, Candle, Cindy, Cinober, Kinnan, Fager, Olsok, Thule, StS 2-11, SW 2904, Glacier ja HA-d). Ohranäytteet toimittivat Graminor AS (Bjørke, Norway) ja Western Plant Breeders (Bozeman, USA). Jyvät jauhettiin ja niistä määritettiin kemiallinen koostumus sekä eristettiin neutraalidetergenttiin liukenematon jäännös eli solunseinäaines sulatusnopeuden määrittämistä varten.

Sulatusnopeudet mitattiin in vitro -kaasuntuotantomenetelmällä MTT/ERA:n laboratoriossa sekä jauhetuista jyvistä että niistä eristetyistä kuitunäytteistä. Menetelmässä rehunäytettä inkuboidaan kolmen vuorokauden ajan kasvatusliuoksessa, jossa pötsinesteen mikrobit pilkkovat rehunäytettä. Käymisessä syntyvän kaasun määrä mitataan 15 minuutin välein. Tallennetulta kaasukäyrältä rehunäytteelle saadaan ajan suhteen vaihtuva sulatusnopeus, josta edelleen lasketaan vakiosulatusnopeus huomioimalla virtauksen vaikutus pötsisimulaatiolla. Solunsisällyksen sulatusnopeus määritettiin laskemalla solunsisällysaineille kaasuntuotantokäyrä erotuksena kokonäytteen ja kuidun kaasuntuotantokäyrien välillä.

Ohralajikkeiden välillä havaittiin tilastollisesti merkitseviä $(p<0.01)$ eroja sekä jyvien solunsisällyksen että jyvän kuidun sulatusnopeuksissa. Solunsisällyksen sulatusnopeus oli näytteillä keskimäärin $0.14 \mathrm{~h}^{-1}$ ja kuidun keskimäärin $0.066 \mathrm{~h}^{-1}$. Erot eri lajikkeiden solunsisällyksen sulatusnopeuksissa olivat kuitenkin pieniä käytännön kannalta (min-maks $0.13-0.15 \mathrm{~h}^{-1}$ ). Selvästi suurempia eroja lajikkeiden välillä oli kuidun sulatusnopeudessa (min-maks $0.043-0.095 \mathrm{~h}^{-1}$ ). Lajikkeet poikkesivat toisistaan myös kemiallisen koostumuksen osalta. Vaihteluvälit näytteiden koostumuksissa olivat: tärkkelyspitoisuus 470 - 640, valkuaispitoisuus 127 - 169, rasvapitoisuus 18 28 ja NDF-pitoisuus $86-213 \mathrm{~g} / \mathrm{kg} \mathrm{ka}$.

Erot kuidun sulatusnopeuksissa olivat yhteydessä kemialliseen koostumukseen, mutta koska tilastollisesti merkitseviä yhteyksiä oli useita ja koostumustiedot olivat voimakkaasti korreloituneet keskenään, ei näiden alustavien tulosten perusteella voida tehdä johtopäätöksiä ohran kuidun sulatusnopeusvaihtelun yhteydestä kemialliseen koostumukseen.

Havaitut isot erot ohralajikkeiden välillä jyvän kuidun sulatusnopeuksissa antavat aihetta kokeen toistamiselle kotimaisella ohra-aineistolla. Erot voivat olla merkityksellisiä rehuohralajikkeiden valinnassa ja jalostuksessa.

Asiasanat: Ohra, lajike, rehuvilja, jyvä, kuitu, solunsisällys, sulatusnopeus, in vitro 


\section{Johdanto}

Koska tavallisilla dieeteillä solunsisällysaineiden todellinen sulavuus lypsylehmän ruuansulatuskanavassa on lähes $100 \%$ (Van Soest 1967), on suurin osa sulavuuden vaihtelusta peräisin kuidun osuudesta dieetissä sekä kuidun sulavuuden vaihtelusta. Rehun omista ominaisuuksia kuidun sulavuuteen vaikuttavat potentiaalinen kuidun sulavuus sekä potentiaalisesti sulavan kuidun sulatusnopeus. Potentiaalinen kuidun sulavuus on teoreettinen maksimi, johon päästäisiin, jollei aika rajoittaisi sulatusta (Mertens 1993). Koska toteutunut sulavuus on virtauksen ja sulatuksen välistä kilpailua, on kuidun sulatusnopeus oleellinen parametri, jota voidaan hyödyntää dynaamisissa rehuarvojärjestelmissä.

Vaikka pääosa lypsylehmien kuidun saannista tuleekin yleensä karkearehuista, voi korkeilla väkirehutasoilla lypsylehmä saada useita kiloja päivässä myös väkirehun kuitua, josta ohran jyvän kuorikerroksen kuitu voi muodostaa jopa pari kiloa. Luotettavat tutkimusmenetelmät väkirehujen sulatuskinetiikan selvittämiseksi ovat aiemmin olleet vähissä, sillä in vivo kokeissa väkirehuja ei voida syöttää ainoana rehuna eikä erotuksella laskettuja tuloksia voida pitää kovin luotettavina yhdysvaikutusten vuoksi. Yleisesti on käytetty in situ menetelmää, jossa rehunäytettä punnitaan synteettiseen huokoiseen pussiin, joka laitetaan pötsifistelin kautta pötsiin tietyksi ajaksi. Menetelmä on kuitenkin useissa kokeissa aliarvioinut kuidun sulatusnopeuden verrattuna in vivo tuloksiin (Huhtanen 1997). Lisäksi monet seikat menetelmässä vaikuttavat saatuihin tuloksiin (Michalet-Doreau ja Ould-Bah 1992, Huntington ja Givens 1995, Vanzant ym. 1998), väkirehuilla erityisesti partikkelihävikki saattaa vääristää tuloksia. Menetelmien puuttuessa luotettavat mittaustulokset väkirehujen kuidun sulatusnopeuksista ovatkin olleet niukkoja.

In vitro -kaasuntuotantomenetelmässä jäljitellään pötsin sulatustapahtumia koeputkessa. Rehunäytettä inkuboidaan kasvatusliuoksessa, johon on lisätty pötsinesteinokulantti. Menetelmä perustuu siihen, että käymisessä hajotetun orgaanisen aineen määrä korreloi käymisessä vapautuneen kaasumäärän kanssa. Mittaamalla kaasuntuotanto ajan funktiona, voidaan menetelmällä määrittää sulatuskinetiikka myös väkirehuista. Kaasuntuotannon mittaamisen automatisoinnin myötä menetelmästä on tullut kilpailukykyinen. Kun mittaustulosten laskenta yhdistetään dynaamiseen pötsin sulatustapahtumien mallintamiseen voidaan edelleen parantaa menetelmän käyttökelpoisuutta helpottamalla tulosten tulkintaa.

Tässä tutkimuksessa selvitettiin in vitro -kaasuntuotantomenetelmällä eri ohralajikkeiden jyvien välisiä eroja solun sisällyksen ja kuidun sulatusnopeuksissa. Tutkimus tehtiin osana isompaa tutkimushanketta ja yhteistyötahona oli Norwegian University of Life Sciences.

\section{Aineisto ja menetelmät}

Kokeessa oli mukana 12 ohralajiketta (Alamo, Candle, Cindy, Cinober, Kinnan, Fager, Olsok, Thule, StS 2-11, SW 2904, Glacier ja HA-d). Ohranäytteet toimittivat Graminor AS (Bjørke, Norway) ja Western Plant Breeders (Bozeman, USA). Jyvät jauhettiin ja niistä määritettiin kemiallinen koostumus sekä eristettiin neutraalidetergenttiin liukenematon jäännös eli solunseinäaines sulatusnopeuden määrittämistä varten.

Sulatusnopeudet mitattiin in vitro kaasuntuotantomenetelmällä (Getachew ym. 1998, Williams 2000) MTT/ERA:n laboratoriossa sekä jauhetuista jyvistä että niistä eristetyistä kuitunäytteistä. Menetelmässä rehunäytettä inkuboidaan kolmen vuorokauden ajan kasvatusliuoksessa, jossa pötsinesteen mikrobit pilkkovat rehunäytettä. Käymisessä syntyvän kaasun määrä mitataan 15 minuutin välein. Tallennetulta kaasukäyrältä rehunäytteelle saadaan ajan suhteen vaihtuva sulatusnopeus, josta edelleen lasketaan vakiosulatusnopeus huomioimalla virtauksen vaikutus pötsisimulaatiolla. Pötsisimulaatiossa sulatuspooleja oli kaksi vastaten rehun valikoivaa viipymistä pötsissä. Kokonaisviipymisaika pötsimallissa $(31,3 \mathrm{~h})$ vastasi väkirehujen viipymisaikaa Karolinelehmämallissa (pohjoismaisena yhteistyönä luotu dynaaminen malli lypsylehmän aineenvaihdunnasta, Danfær et al. 2005). Solunsisällyksen sulatusnopeus määritettiin laskemalla solunsisällysaineille kaasuntuotantokäyrä erotuksena kokonäytteen ja kuidun kaasuntuotantokäyrien välillä.

Sulatusnopeuksien LS-keskiarvot laskettiin SAS-ohjelman (1999) MIXED-proseduurilla sovittaen aineistoon malli $\mathrm{P}_{\mathrm{ijk}}=\mu+\mathrm{R}_{\mathrm{i}}+\mathrm{C}_{\mathrm{k}}+\varepsilon_{\mathrm{ijk}}$, jossa $\mathrm{P}_{\mathrm{ijk}}$ on sulatusnopeus, $\mu$ on yleiskeskiarvo, $\mathrm{R}_{\mathrm{i}}$ on inkubaatiokerran vaikutus, $\mathrm{C}_{\mathrm{k}}$ on lajike ja $\varepsilon_{\mathrm{ijk}}$ kuvaa virhevaihtelua. Inkubaatiokerta oli mallissa 
satunnaistekijä ja muut kiinteitä tekijöitä. Kemiallisen koostumuksen yhteyttä sulatusnopeuteen selvitettiin laskemalla Pearsonin korrelaatiokertoimet parametrien välillä ja sovittamalla MIXEDproseduurilla aineistoon malli $\mathrm{P}_{\mathrm{im}}=\mu+\mathrm{R}_{\mathrm{i}}+\alpha_{1} \cdot \mathrm{D}_{\text {lim }}+\varepsilon_{\mathrm{im}}$, jossa $\mathrm{D}_{\text {lim }}$ on näytteestä mitatun kemiallisen koostumuksen $\mathrm{D}_{1}$ arvo $\mathrm{m}$ inkubaatiokerralla $\mathrm{i}, \alpha_{1}$ on regressiokerroin, joka on sama kaikilla inkubaatiokerroilla ja muut parametrit ovat kuten LS-keskiarvoja laskettaessa. Eri kemiallisten parametrien (kuitu-, valkuais-, rasva- ja tärkkelyspitoisuus) yhteyttä sulatusnopeuteen analysoitiin erikseen sovittamalla kullekin oma malli. Eri malleja verrattiin edelleen keskenään laskemalla yksinkertainen regressio sekamallilla ennustettujen arvojen ja mitattujen arvojen välille. Sekamallien käytöstä on kirjoittanut tarkemmin St-Pierre (2001).

\section{Alustavat tulokset}

Ohralajikkeiden välillä havaittiin tilastollisesti merkitseviä $(p<0.01)$ eroja sekä jyvien solunsisällyksen että jyvän kuidun sulatusnopeuksissa. Solunsisällyksen sulatusnopeus oli näytteillä keskimäärin 0.14 $\mathrm{h}^{-1}$ ja kuidun keskimäärin $0.066 \mathrm{~h}^{-1}$. Erot eri lajikkeiden solunsisällyksen sulatusnopeuksissa olivat kuitenkin pieniä käytännön kannalta (min-maks $0.13-0.15 \mathrm{~h}^{-1}$ ). Selvästi suurempia eroja lajikkeiden välillä oli kuidun sulatusnopeudessa (min-maks $0.043-0.095 \mathrm{~h}^{-1}$ ). Lajikkeet poikkesivat toisistaan myös kemiallisen koostumuksen osalta, vaihteluvälit näytteiden koostumuksissa olivat: tärkkelyspitoisuus 470 - 640, valkuaispitoisuus 127 - 169, rasvapitoisuus 18 - 28 ja NDF-pitoisuus 86 - 213 g/kg ka (Taulukko 1, Kuva 1).

Yhteydet näytteiden kemiallisen koostumuksen ja kuidun sulatusnopeuden välillä olivat voimakkaita (Taulukko 2). Myös koostumustiedot olivat voimakkaasti korreloituneet keskenään (Taulukko 3).

Taulukko 1. Ohralajikkeiden jyvien kemiallinen koostumus ja mitatut sulatusnopeudet.

\begin{tabular}{lcccccc}
\hline Lajike & $\begin{array}{c}\text { Kjeldahl-N } \\
\mathrm{g} / \mathrm{kg} \mathrm{ka}\end{array}$ & $\begin{array}{c}\text { Raakarasva } \\
\mathrm{g} / \mathrm{kg} \mathrm{ka}\end{array}$ & $\begin{array}{c}\text { Tärkkelys } \\
\mathrm{g} / \mathrm{kg} \mathrm{ka}\end{array}$ & $\begin{array}{c}\mathrm{NDF} \\
\mathrm{g} / \mathrm{kg} \mathrm{ka}\end{array}$ & $\begin{array}{c}\mathrm{Kd}_{\mathrm{ss}} \mathrm{h}^{-1} \\
\mathrm{Kd}_{\mathrm{NDF}}{ }^{2} \\
\mathrm{~h}^{-1}\end{array}$ \\
\hline Kinnan & 23.4 & 23.1 & 583 & 167 & 0.139 & 0.0583 \\
Fager & 31.3 & 21.8 & 591 & 178 & 0.141 & 0.0520 \\
Olsok & 23.9 & 18.4 & 564 & 176 & 0.134 & 0.0574 \\
Thule & 23.7 & 20.8 & 551 & 198 & 0.140 & 0.0569 \\
Alamo & 27.0 & 25.0 & 592 & 104 & 0.153 & 0.0955 \\
Candle & 24.6 & 25.7 & 623 & 86 & 0.145 & 0.0918 \\
Cindy & 21.6 & 23.2 & 602 & 133 & 0.146 & 0.0708 \\
Cinober & 25.9 & 23.4 & 640 & 95 & 0.154 & 0.0905 \\
StS 2-11 & 24.9 & 28.0 & 554 & 175 & 0.143 & 0.0609 \\
SW 2904 & 21.2 & 26.0 & 568 & 168 & 0.137 & 0.0646 \\
Glacier & 20.3 & 23.1 & 512 & 199 & 0.136 & 0.0454 \\
HA-d & 24.1 & 26.3 & 470 & 214 & 0.135 & 0.0431 \\
p-arvo & & & & & 0.0012 & $<0.0001$ \\
Std Err & & & & & 0.0076 & 0.0041 \\
\hline
\end{tabular}

\footnotetext{
${ }^{1}$ Solunsisällyksen sulatusnopeus

${ }^{2}$ Kuidun sulatusnopeus
} 
Taulukko 2. Ohranjyvien kemiallisen koostumuksen ( $\mathrm{g} / \mathrm{kg} \mathrm{ka})$ yhteys kuidun sulatusnopeuteen $\left(\mathrm{h}^{-1}\right)$. Aineistoon sovitettu lineaarinen yhtälö ( $\mathrm{Y}=\mathrm{A}+\mathrm{BX})$.

\begin{tabular}{lcccccccc}
\hline & $\mathrm{n}$ & $\mathrm{A}$ & $\mathrm{S} . \mathrm{E}$. & $\mathrm{B}$ & $\mathrm{S} . \mathrm{E}$. & $\mathrm{p}$ & $\mathrm{R}^{2}$ malli* & RMSE* $^{*}$ \\
\hline NDF & 36 & 0.130 & 0.0050 & -0.00041 & 0.000024 & $<0.0001$ & 0.894 & 0.0058 \\
Rasva & 36 & 0.033 & 0.0286 & 0.00139 & 0.001196 & 0.2534 & 0.010 & 0.0182 \\
Tärkkelys & 36 & -0.109 & 0.0251 & 0.00031 & 0.000044 & $<0.0001$ & 0.587 & 0.0115 \\
Valkuainen & 36 & -0.067 & 0.0295 & 0.00090 & 0.000200 & $<0.0001$ & 0.363 & 0.0144 \\
\hline
\end{tabular}

* Laskettu regressiolla sekamallilla ennustettujen arvojen ja mitattujen arvojen välille.

Taulukko 3. Ohranjyvien kemiallisen koostumuksen (g/kg ka) ja kuidun sulatusnopeuden $\left(\mathrm{h}^{-1}\right)$ Pearssonin korrelaatiokertoimet. Lihavoidut korrelaatiokertoimen arvot ovat tilastollisesti merkitseviä $(\mathrm{p}<0.05)$.

\begin{tabular}{lcccc}
\hline & Valkuainen & Tärkkelys & Rasva & $\mathrm{Kd}_{\mathrm{NDF}}{ }^{1} \mathrm{~h}^{-1}$ \\
\hline NDF & -0.519 & $\mathbf{- 0 . 8 5 5}$ & -0.169 & $\mathbf{- 0 . 9 6 8}$ \\
Valkuainen & & 0.289 & 0.208 & $\mathbf{0 . 6 3 7}$ \\
Tärkkelys & & & -0.123 & $\mathbf{0 . 7 9 4}$ \\
Rasva & & & & 0.206 \\
\hline
\end{tabular}

${ }^{1}$ Kuidun sulatusnopeus

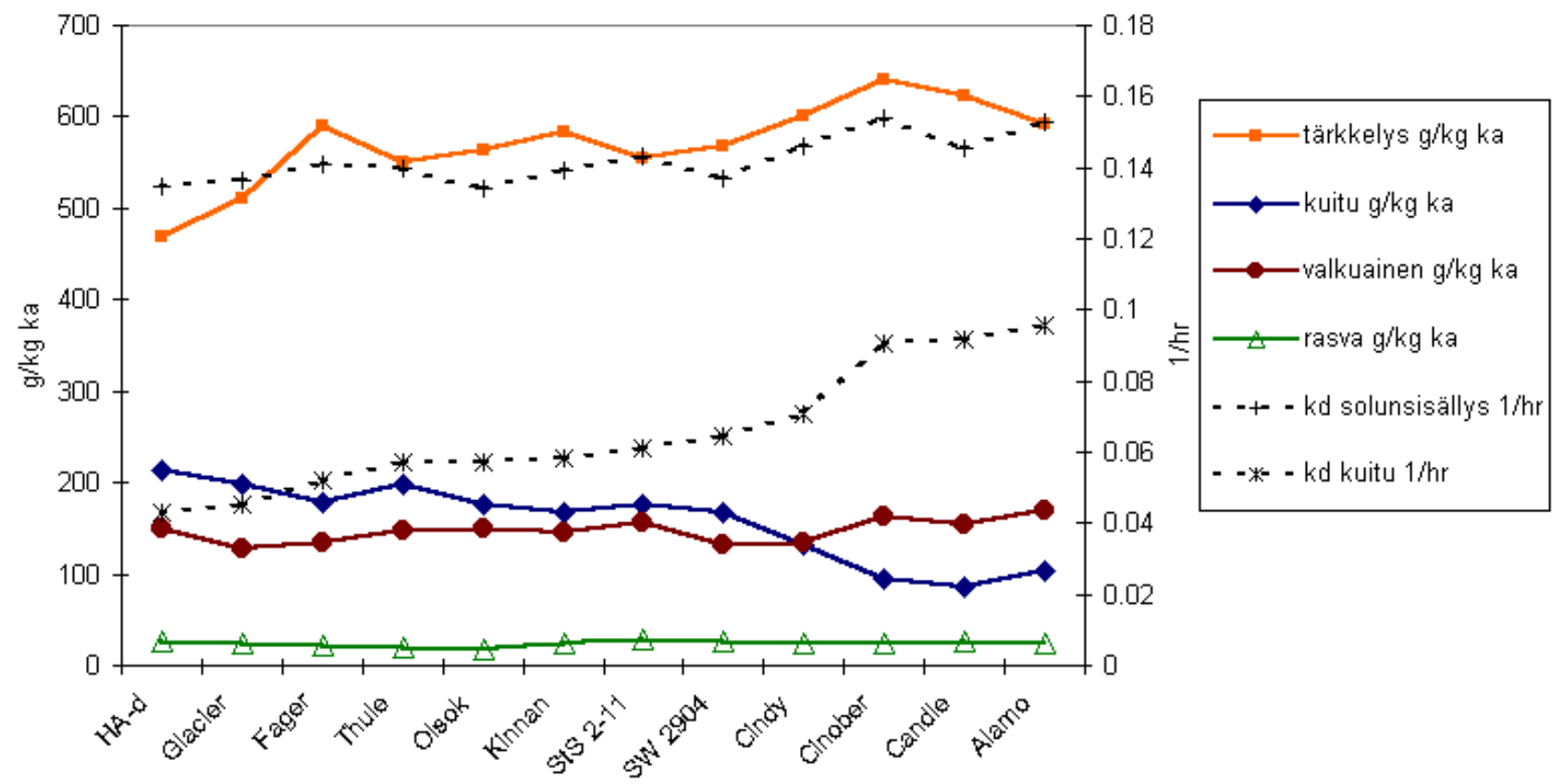

Kuva 1. Ohranjyvien kemiallinen koostumus sekä kuidun ja solunsisällyksen sulatusnopeudet 


\section{Tulosten tarkastelu}

Havaitut erot jyvän kuidun sulatusnopeuksissa vastaavat potentiaalisesti sulavan kuidun sulavuudessa vaihtelua 626 - $822 \mathrm{~g} / \mathrm{kg}$. Valitettavasti aineistosta ei mitattu kuidun potentiaalista sulavuutta, joka olisi oleellinen parametri, jotta saataisiin kokonaiskuva ohran kuidun sulavuudesta. Kuitenkin, mikäli lypsylehmä saa dieetissään ohran kuitua $2 \mathrm{~kg}$, voi potentiaalisesti sulavaa siitä olla noin $1.64 \mathrm{~kg}$, jossa määrässä havaittu sulatusnopeuden vaihtelu merkitsisi sulavan orgaanisen aineen saannissa reilua 300 grammaa. Oleellista olisi selvittää onko kuidun sulatusnopeus yhteydessä kuidun potentiaaliseen sulavuuteen.

Erot kuidun sulatusnopeuksissa olivat yhteydessä kemialliseen koostumukseen, mutta koska tilastollisesti merkitseviä yhteyksiä oli useita ja koostumustiedot olivat voimakkaasti korreloituneet keskenään, ei näiden alustavien tulosten perusteella voida tehdä johtopäätöksiä ohran kuidun sulatusnopeusvaihtelun yhteydestä kemialliseen koostumukseen.

\section{Johtopäätökset}

Havaitut isot erot ohralajikkeiden välillä jyvän kuidun sulatusnopeuksissa antavat aihetta kokeen toistamiselle kotimaisella ohra-aineistolla. Erot voivat olla merkityksellisiä rehuohralajikkeiden valinnassa ja jalostuksessa.

\section{Kirjallisuus}

Danfær, A., Huhtanen, P., Udén, P. Sveinbjörnsson, J, Volden, H. 2005. Karoline - a Nordic cow model for feed evaluation - model description. In: Kebreab, E. et al. (eds) Nutrient Digestion and Utilization in Farm Animals: Modelling approaches. CAB International, pp. 407-415.

Getachew, G., Blummel, M., Makkar, H.P.S. \& Becker, K. 1998. In vitro gas measuring techniques for assessment of nutritional quality of feeds: a review. Anim. Feed Sci. Technol. 72: 261-281.

Huhtanen, P. 1997. Methods in assessing the parameters of digestion and passage kinetics in the rumen and utilisation of these parameters in digestion models. Julkaisussa: In vitro and in vivo methods used in experiments on digestion processes and feed evaluation: international seminar: 3-4 October 1996, Balice near Krakow, Poland. Toim. A. Antoniewicz \& K. Sokol. p. 89-98.

Huntington, J.A. \& Givens, D.I. 1995. The in situ technique for studying the rumen degradation of feeds: a review of the procedure. Nutrition Abstracts and Rewiews (Series B) 65 (2), 63-93.

Mertens, D.R. 1993. Rate and extend of digestion. Julkaisussa: Quantitative aspects of ruminant digestion and metabolism. Toim. J.M. Forbes \& J. France, s. 13-51.

Michalet-Doreau, B. \& Ould-Bah, M.Y. 1992. In vitro and in sacco methods for the estimation of dietary nitrogen degradability in the rumen: a review. Anim. Feed Sci. Technol. 40: 57-86.

SAS 1999-2001. SAS (r) Proprietary Software Release 8.2, SAS Institute Inc., Cary, NC, USA.

St-Pierre, N.R., 2001. Integrating quantitative findings from multiple studies using mixed model methodology. J. Dairy Sci. 84: 741-755.

Vanzant, E.S., Cochran, R.C. \& Titgemeyer, E.C. 1998. Standardization of in situ techniques for ruminant feedstuff evaluation. J. Anim. Sci. 76: 2717-2729.

Van Soest, P.J. 1967. Development of a comprehensive system of feed analyses and its application to forages. J. Anim. Sci. 26: 119-128.

Williams, B.A. 2000. Cumulative gas-production techniques for forage evaluation. Julkaisussa: Forage evaluation in ruminant nutrition. CAB International. Toim. D.I. Givens, E. Owen, R.F.E. Axford \& H.M. Omed. s. $189-213$. 